\title{
Factors Affect Dye Sensitized Solar Cells performance
}

\author{
Ahmed A. Mohamed ${ }^{1}$, Yehia Selim² \\ ${ }^{1}$ Faculty of Engineering, Pharos University, Alexandria, Egypt \\ ${ }^{2}$ Faculty of Engineering, Menoufia University, Shebin El-Kom, Egypt \\ Ameny_49@yahoo.com, yehia.selim@pua.edu.eg
}

\begin{abstract}
Recently, dye-sensitized solar cells (DSSCs) have received great attention for their simple fabrication process, low production costs and, relatively high conversion efficiency.

DSSC are a combination of materials, consisting of a transparent electrode coated with a dye-sensitized mesoporous film of nanocrystalline particles of $\mathrm{TiO} 2$, an electrolyte containing a suitable redox couple and an electrode. In order to optimize DSSC performance, it is important to fully understand the factors which affect the key features of DSSC characteristics.
\end{abstract}

This paper presents an overview of the construction of a dye-sensitized solar cell, operating principle of DSSC, DSSC performance and, investigates the most important parameters which affect Dye-Sensitized Solar Cells performance.

Keywords - dye-sensitized solar cells, DSSC performance, dye, Factors improve DSSC efficiency

\section{INTRODUCTION}

Traditional energy sources (fossil full) face a number of challenges such as:

- Increasing energy demand;

- Fuel depletion.

- Climate change; and

- Pollution and public-health hazards.

From an environmental perspective, renewable energy source is an alternative source to the conventional energy sources.

Solar energy sources are considered one of the most promising renewable sources [1-6], since solar energy sources are clean, inexhaustible, environment friendly, plentiful and easy to utilize. Also, solar energy sources can provide electricity in remote areas where electricity is not available.
Solar cells give us the easier way to utilize the enormous source of renewable energy. Solar cells are considered a best choice of solar energy since it cuts-down electricity bill, needs low maintenance, produces no pollution, no emission and no noise.

Solar cells are usually divided into three main categories called generations [7]. As shown in Figure (1), first generation solar cells are mainly based on silicon wafers and its efficiency is about 15-25 $\%$.These types of solar cells dominate the market. The benefits of this solar cell technology lie in their good performance, as well as their high stability. However, they are rigid, relatively expensive to produce, have a low efficiency, and are more at risk to lose some of their efficiency at higher temperatures.

Second generation solar cells is used to produce a cheaper solar cell by applying thin-film technology. These solar cells use less material and lower cost manufacturing processes compared to the first generation solar cells. However the 2nd generation solar cells have significant limitations, including lower overall efficiency compared to 1st generation and the toxicity of the component materials used.

The goal of third generation technologies is to enhance poor electrical performance of second generation (thin-film technologies) while maintaining very low production costs.

3rd generation solar cells, are based on nanostructured materials and they are made of purely organic or a mixture of organic and inorganic components, thus allowing for a vast and inexhaustible choice of materials.

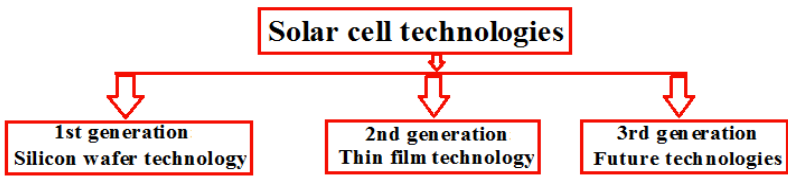

Fig. 1. Solar cells technologies 
There are four types of third-generation PV technologies:

- Nanocrystal solar cells

- Polymer solar cells

- Dye sensitized solar cells

- Concentrated solar cells

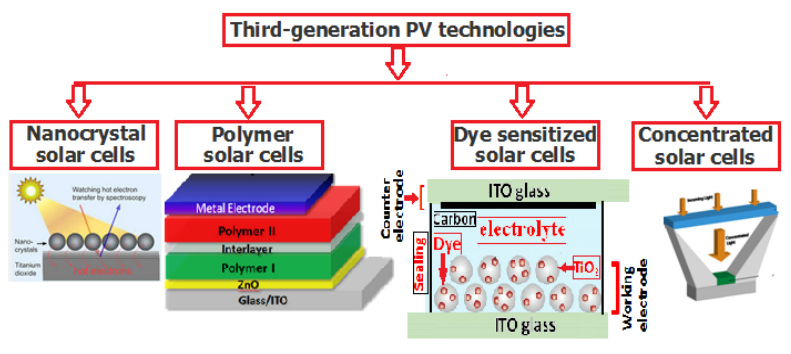

Fig. 2. Third-generation PV technologies

Among the different possibilities of 3rd generation solar cells, Dye sensitized solar cells (DSSCs) have the most promising prospect.

Manufacturing of DSSC is simple, mostly low cost, and incorporate environmentally friendly materials. DSSC uses an organic dye to produce electricity in a wide range of light conditions, indoors and outdoors.

However, a major drawback is the temperature sensitivity of the liquid electrolyte. Hence a lot of research is going on to improve the electrolyte's performance and cell stability.

This paper presents an overview of

- Construction of a dye-sensitized solar cell ,

- Operating principle of DSSC,

- DSSC performance

- The factors affect performance of Dye Solar Cells.

\section{CONSTRUCTION OF A DYE-SENSITIZED SOLAR CELL}

DSSC has 3 primary parts, anode, counter electrode and iodide electrolyte. With a few simple materials, you can create a working solar cell that mimics the process of photosynthesis. Indium Transparent conductive oxide ITO

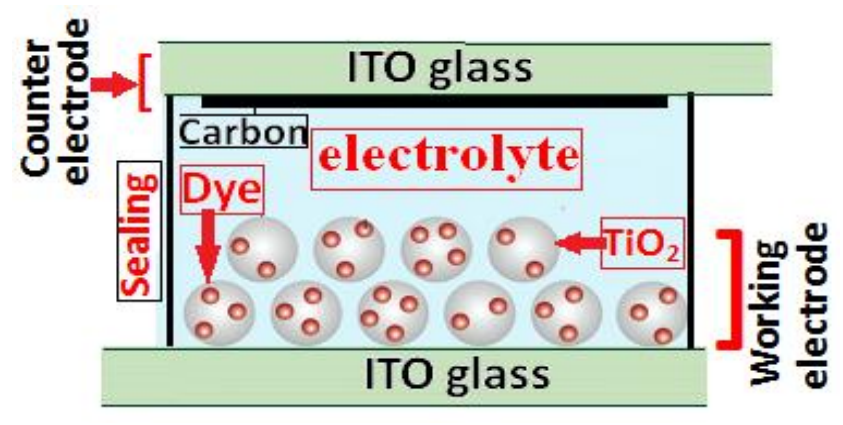

Fig. 3. Construction of a dye-sensitized solar cell

Figure (3) shows the four parts of DSSC which are:

- The electrode film layer (TiO2), covered by a dye molecules, that absorbs solar energy;

- Indium tin oxide (ITO) layer is used to facilitate charge transfer from the electrode layer;

- The counter electrode layer made of C;

- lodide electrolyte it used to supply electrons to dye to replace the ones being extracted by $\mathrm{TiO} 2$.

\section{OPERATING PRINCIPLE OF A DYE- SENSITIZED SOLAR CELL (DSSC)}

With aid of Figure (4), the operating principle of a dye-sensitized solar cell (DSSC) is explained as follows:

- $\quad$ Light strikes the dye molecules.

- If the photon has enough energy, it will excite an electron from the dye, which is transmitted into the conduction band of the $\mathrm{TiO} 2$.

- The electrons will be collected by front electrode and supplied to external circuit to the counter electrode.

- The counter electrode returns electrons from the external circuit back to the cycling current in the cell.

- The original state of the dye is subsequently restored by electron transferred from the redox electrolyte.

- The electrolyte itself is restored to its original state by an electron coming from counter electrode.

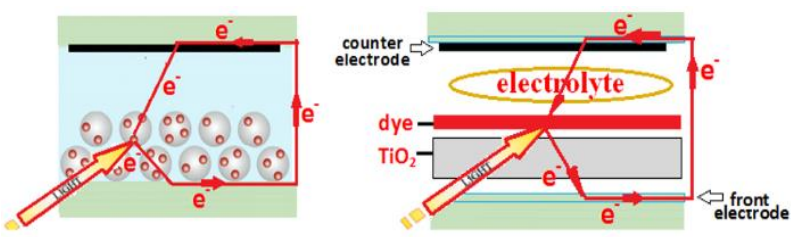

Fig. 4. Working principle of DSSC 
Generation of electrical power under illumination is achieved by the capability of DSSC to produce voltage over an external load and current through the load at the same time. DSSC is characterized by current-voltage $(\mathrm{J}-\mathrm{V})$ curve and $(\mathrm{P}-\mathrm{V})$ curve of the cell as shown in figure (5) [8]:

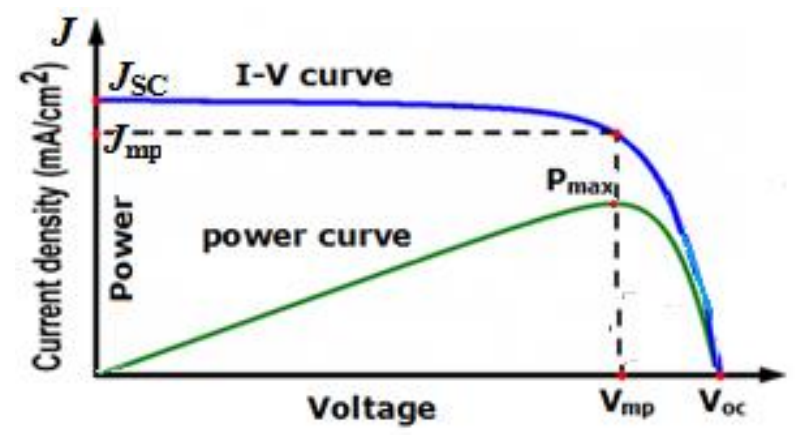

Fig. 5. Current-voltage $(\mathrm{J}-\mathrm{V})$ curve and $(\mathrm{P}-\mathrm{V})$ curve of the cell

In this Figure, When the cell is short circuited under illumination, the maximum current (short circuit ISC) or short circuit current density ( JSC) is generated, while under open circuit conditions no current can flow and the voltage (open circuit voltage, VOC) is at its maximum .

Also in this figure, DSSC output power increases with increase in value of voltage /current density, reaches a maximum value at optimum value of voltage /current density and then starts decreasing, reaches zero value at open circuit voltage/short circuit current. The maximum power point can be obtained by determining the maxima of output power (Pmax) where Pmax is equal to

$P_{\max }=V_{m p} I_{m p}=V_{m p} J_{m p} A_{c e l l}$

Where:

$I_{m p}=$ the current at the maximum power output

$J_{\mathrm{mp}}=$ the current density at the maximum power output

$\mathrm{V}_{\mathrm{mp}}=$ the voltage at the maximum power output

$\mathrm{A}_{\text {cell }}=$ the illuminated cell area

The value of conversion efficiency of prepared dye sensitized solar cells was measured from Eq. (1), were $\eta$ is overall conversion efficiency and VOC, ISC, FF, Pin are the open-circuit voltage, short-circuit current density, fill factor and the intensity of incident light, respectively.

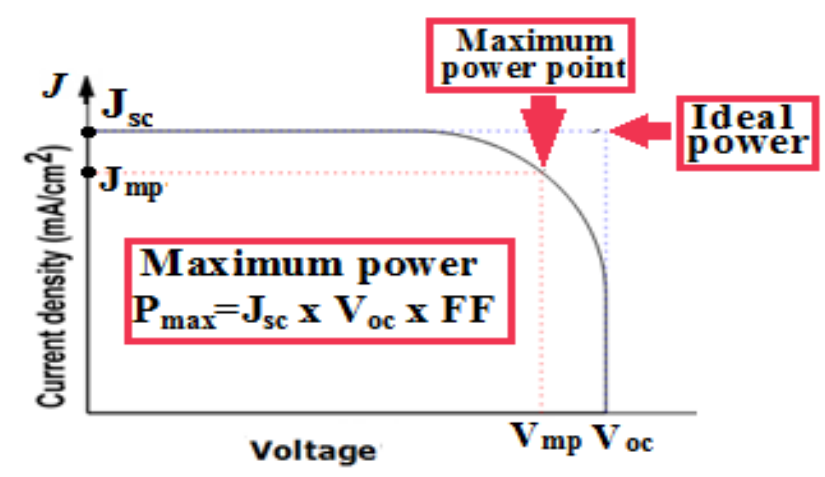

Fig. 6. Performance of DSSC

Figure (6) illustrates the performance of DSSCs, and the solar power $(P)$ can be calculated by the equation: $P=I V$

The energy conversion efficiency of DSSCs is described by the ratio of the maximum electrical power output $P_{\max }$ to the solar energy input Pin. The maximum electrical power output $P_{\max }$ is calculated by the maximum current $\mathrm{J}_{\mathrm{mp}}$ and the maximum voltage $\mathrm{V}_{\mathrm{mp}}$ :

$P_{\max }=J_{m p} \times V_{m p}$

The solar power input is taken as the product of the irradiance of the incident light that is measured in $\mathrm{W} / \mathrm{m} 2$ :

$\eta=\frac{P_{\text {max }}}{P_{\text {in }}} \times 100=\frac{J_{\text {mp }} \cdot V_{\text {mp }}}{P_{\text {in }}} \times 100$

The fill factor FF is index of loss electric generation or a measure of the quality of the solar cell, and it can be calculated by comparing the maximum shortcircuit current Jsc and maximum open-circuit voltage $\mathrm{Voc}$ to the maximum current Jmp and maximum voltage Vmp:

$$
\mathbf{F F}=\frac{P_{\max }}{J_{s c} \cdot V_{o c}}=\frac{J_{m p} \cdot V_{m p}}{J_{s c} \cdot V_{o c}}
$$

By subsuming Eq. (2) into Eq. (1),

$$
\eta=\frac{J_{\text {sc. }} V_{\text {oc. }} \text { FF }}{P_{\text {in }}} \times 100
$$

The ideal power density of DSSCs is the product of Jsc and Voc. The maximum power density is the product of Jmp and Vmp, and the difference between the two comes from the resistances of the cell, electrolyte, electrode, and other components. The energy conversion efficiency of DSSCs is related 
to the ideal power density and maximum power density as shown in Figure (6). When the fill factor is equal to 1, Jsc and Voc are the same as Jmp and $\mathrm{Vmp}$. The series resistance Rs includes the cell, electrolyte, electrode, and interface resistance.

\section{FACTORS IMPROVE DSSC EFFICIENCY}

The DSSC contains several different components: A conducting glass substrate, a mesoporous semiconductor film, a sensitizer, an electrolyte with a redox couple and a counter electrode. The optimization of each of them is of great importance in order to improve the overall efficiency.

Figure (7) presents best properties of each of the materials which constitute the DSSC of the overall process for energy conversion.

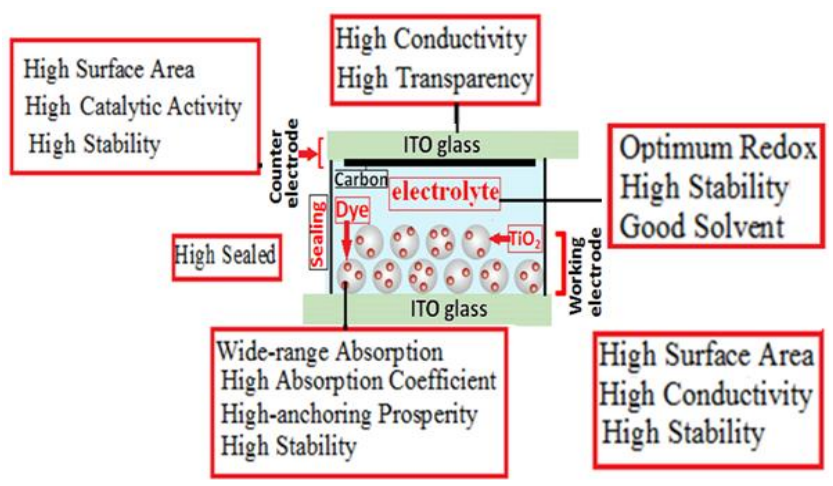

Fig. 7. The property of each DSSC components

A lot of researchers do all affords to satisfy the requirement properties of each DSSC's components [9]. Unfortunately, the researchers affords don't give a significant increase. But from my view if a cooroperation between Electrical, Chemical and Mechanical departments is done a good result is expected.

\section{CONCLUSIONS}

The potential for improvement in the power conversion efficiency of DSSC is regarded as a highly promising method for efficient and economical conversion of light in to electrical energy.

The DSSC contains several different components; the optimization of each of these components is of great importance to improve the overall efficiency.

The key requirements for efficient sensitization needs examination of numerous dyes of different chemical structure and functional groups.
Determination of the absorption spectrum of the dye and its stability are most important components influencing solar cell performance.

Investigations of Influence of physical factors affected DSSC performance require co working between scientific branches (Electrical, Chemical and Mechanical).

\section{REFERENCES}

[1] Solar Electricity Handbook, Michael Boxwell, Greenstream Publishing, 2016 Edition

[2] Solar Energy in Developing Countries: Perspectives and Prospects :

[3] a Report ...By National Academy of Sciences (U.S.). Board on Science and Technology for International.

[4] Solar Engineering of Thermal Processes. John A. Duffie, William A. Beckman. Wiley, 1991.

[5] Karim Hegazy, Egypt's Energy Sector - Energy Charter, Energy Charter Secretariat Knowledge Centre 2015, ISSN: 2406-6087

[6] Egypt Crisis in the energy sector, economicresearch.bnpparibas.com/October 2013

[7] Solar Energy in Egypt Advantages and Obstacles www.numov.org/de/...al/.../616-5-drsamir-ayad-egyptian-solar-energy-systems-co

[8] 3 Generations of Solar Cells: Solar Facts and Advice,

[9] www.solar-facts-and-advice.com/solar-cells.

[10] P.M. Sommeling, H.C. Rieffe, Spectral response and IV-characterization of dye-sensitized nanocrystalline $\mathrm{TiO} 2$ solar cells, Solar Energy Materials \& Solar Cells 62 (2000).

[11] Claudia Longo; Marco-A. De Paoli, Dyesensitized solar cells: a successful combination of materials , J. Braz. Chem. Soc. vol.14 no.6 São Paulo Nov./Dec. 2003. 